\title{
Assessment of Dietary Habits and Nutritional Status of Adolescents in a Resource - Poor Environment in Nigeria
}

\author{
Sarah Iyoefo Iyalomhe ${ }^{1, *}$, Samuel Esiemokhai Iyalomhe ${ }^{2}$, Ifeanyi Godwin Nwadike ${ }^{1}$, \\ Rosemary Ngozi Osunde ${ }^{1}$, Godfrey Bolade Samuel Iyalomhe ${ }^{3}$ \\ ${ }^{1}$ Department of Nursing Science, College of Medicine, Ambrose Alli University, Ekpoma, Nigeria \\ ${ }^{2}$ Department of Community Medicine, College of Medicine, Ambrose Alli University, Ekpoma, Nigeria \\ ${ }^{3}$ Department of Pharmacology \& Therapeutics, College of Medicine, Ambrose Alli University, Ekpoma, Nigeria
}

Email address:

sarahiyalo@yahoo.com (S. I. Iyalomhe), okhaisamuel@yahoo.com (S. E. Iyalomhe), nwadike100@gmail.com (I. G. Nwadike), ngosunde23@gmail.com (R. N. Osunde), goddyiyalo@yahoo.com (G. B. S. Iyalomhe)

${ }^{*}$ Corresponding author

To cite this article:

Sarah Iyoefo Iyalomhe, Samuel Esiemokhai Iyalomhe, Ifeanyi Godwin Nwadike, Rosemary Ngozi Osunde, Godfrey Bolade Samuel Iyalomhe. Assessment of Dietary Habits and Nutritional Status of Adolescents in a Resource - Poor Environment in Nigeria. International Journal of Nutrition and Food Sciences. Vol. 7, No. 4, 2018, pp. 121-128. doi: 10.11648/j.jjnfs.20180704.12

Received: May 31, 2018; Accepted: June 20, 2018; Published: July 7, 2018

\begin{abstract}
Information is scarce about dietary habits and nutritional status in adolescents in Ekpoma, Nigeria. This is partly because of this age group's reputation for capriciousness and also because health services/research in developing countries tend to focus more on pre-school children and pregnant women. This study aimed to optimize the health needs of Nigerian adolescents by determining the dietary habits and the nutritional status of adolescents using anthropometry. The cross-sectional descriptive study engaged 400 adolescents aged 10 - 19 years in four secondary schools in Ekpoma using a semi-structured questionnaire for data collection. Height $\left(\mathrm{m}^{2}\right)$ and weight $(\mathrm{kg})$ were measured and body mass index (BMI) was computed to assess underweight, normal weight, over-weight or obesity. SPSS was used to analyse data. Important factors affecting dietary habits include parental influence $(87 \%)$, taste of food $(71 \%)$, mass media reports $(61 \%)$ and culture $(55 \%)$. Percentages of underweight, normal weight, overweight, and obese adolescents were $24 \%, 72 \%, 3 \%$ and $1 \%$, respectively. There was significant association between BMI and monthly household income, $\mathrm{p}<0.002$. There were no significant gender differences. In contrast to the rising prevalence of obesity worldwide, this study has demonstrated that under-nutrition is a challenge in this environment. Intensified nutritional education, provision of adequate healthy diets and motivational strategies are imperatives to prevent malnutrition and its related health consequences in this adolescent population - tomorrow's adults.
\end{abstract}

Keywords: Adolescents, Dietary Habits, Nutritional Status, Anthropometry, Nigeria

\section{Introduction}

There is paucity of information as regards dietary habits and nutritional status of adolescents in Ekpoma, Edo State of Nigeria, partly because of this age-group's reputation for capriciousness [1]. Also, for a number of years in Nigeria, the health of adolescents has not been a major concern and hence research in this group has been limited because the adolescents are observed to be less susceptible to disease and suffer from fewer life-threatening ailments than children and the elderly [2]. In fact, adolescence is generally described as a period of relatively good health with low prevalence of infection and chronic diseases [3]. Thus, health services particularly in developing countries tend to focus more on pre-school age children and pregnant women to the detriment of the health needs of adolescents [2-3].

According to the World Health Organization (WHO), an adolescent is a person between 10-19 years of age and the world adolescent population is about 1.2 billion, indicating that one in every five people in the world is an adolescent, with $85 \%$ of them living in developing countries [4]. It is known that the period of adolescence is critical as it encapsulates the window of time when the body is metamorphosing from childhood to adulthood. Hence 
adequate nutrient intake during this period is a desideratum as growing evidence indicates a complex interplay between nutrition and health. In fact, research has shown that the primary causes of chronic diseases are influenced by diet [4$6]$.

The dramatic increase in energy and nutrient requirements coincides with other factors that may affect adolescents' dietary choices and nutrient intake and thus nutritional status [5-8]. These factors, such as the quest for independence and acceptance by peer group (peer pressure), increase mobility, greater time spent at school and/or work activities as well as preoccupation with self-image, contribute to the erratic and unhealthy eating behaviour characteristic of adolescents [9$11]$.

Adolescents may skip meals because of irregular schedules. Breakfast and lunch are the meals most often missed but social, school and work activities can cause meals to be missed as well [2, 4]. Skipping breakfast is a decision that adolescents frequently make and healthy eating is often a low priority or it is totally jettisoned [9-10]. Skipped meals and fewer family meals result in lower intake of nutrients and other food groups (fruits, vegetables and dairy). In focus groups, adolescents associate eating healthy foods with eating family meals and identify parents as having important influences on their dietary habits [12].

Eating habits formed during adolescence can persist into adulthood and can prevent or delay onset of some diseases in future [14]. Hence, adolescents are ideal target for nutrition education, more so as they are known to be curious and open to new ideas [4, 6-9]. In various countries including Nigeria, limited access to healthy and nutritious foods and the appeal of fast food restaurants have been identified as impediments to adolescents' healthy eating [15-16]. According to WHO, the ultimate intention of nutritional assessment is to improve human health $[1,17]$. Adolescents who have been found to have a nutrition-related health challenge or who consume poor quality diets will require in-depth nutritional assessment in order to uncover dietary habits that require modification. Consequently, most appropriate nutritional intervention and the level of motivation to effect the desired change are to be prudently pursued and utilized [17-19].

It is now well established that on a large scale, body mass index (BMI) is the simplest and cheapest way to objectively classify individuals as either underweight, normal weight, overweight or obese. It is a measure of relative weight with reference to the person's height [20-22].

Hence two people can have the same weight but different BMIs because of differences in their height. BMI is defined as weight in kilogram $(\mathrm{kg})$ divided by the square of the person's height in metres $\left(\mathrm{m}^{2}\right)$ [2-3]. People at the extremes of the BMI classification are said to be at increased health risk. For the severely underweight persons, it calls for proper assessment of the cause of the weight loss. Among possible causes are chronic severe malnutrition, malabsorption syndrome, anorexia nervosa, poorly managed HIV/AIDS, tuberculosis and malignant disease. On the obese and morbidly obese scale, factors such as genetic environment and poor lifestyle choices including overeating, and not exercising are to be considered $[3,15,20]$.Thus, to optimize the health needs of adolescents in Ekpoma, Nigeria, we assessed their dietary habits and nutritional status.

\section{Materials and Methods}

\subsection{Study Setting}

The study was carried out in Ekpoma, a semi-urban community and the headquarters of Esan West Local Government Area in Edo State of Nigeria. It has a population of about 130,000 people.

\subsection{Inclusion and Exclusion Criteria}

Those who were eligible for inclusion into this descriptive cross-sectional study were a cohort of 400 adolescent boys and girls aged 10-19 years drawn from 4 Secondary Schools in Ekpoma (Mousco Comprehensive Secondary School, Bonahis Secondary School, Zanna Royal Academy and Ujoelen Grammar School). Students whose ages could not be ascertained, those outside the age bracket of 10-19 years and those who did not give their consent, were excluded.

\subsection{Sample Size}

Sample size was estimated using the Leslie Kish formula [23] for cross-sectional surveys.

$$
\mathrm{N}=\frac{\mathrm{z}^{2} \mathrm{pq}}{\mathrm{d}^{2}}
$$

Where $\mathrm{N}=$ Required sample size

$\mathrm{Z}=$ Confidence level at $95 \%$ (standard value is set at 1.96 ).

$\mathrm{P}=$ Proportion of persons estimated to have a particular characteristic in previous studies.

\section{$\mathrm{q}=1-\mathrm{p}$}

$\mathrm{d}=$ degree of accuracy or margin of error (standard value is set at 0.05).

Since no previous study has been done in this area, we use a $\mathrm{P}$ value of $50 \%$. Therefore, calculating the minimum estimated sample size $\mathrm{N}$ gives:

$$
\begin{gathered}
\mathrm{N}=\frac{1.962 \times 0.5 \times 0.5}{0.05^{2}} \\
\mathrm{~N}=384.16
\end{gathered}
$$

Therefore, the minimum sample size was 384 . Hence a sample size of 400 was used. $^{2}$

\subsection{Sampling Technique}

A multistage sampling technique was used:

One arm of each class (junior and senior) was selected through simple random sampling technique by balloting. Using the class register as the sampling frame, the required number of students from each class (20 students) was selected by simple random sampling using a table of random numbers. 


\subsection{Measurement of Height}

A staff, calibrated in meters, was used to measure height with each adolescent standing erect with head straight, legs put together, with both back and heels touching the wall.

\subsection{Measurement of Weight}

A standard beam balance (Hackman, UK) calibrated in kilogram was used to measure the weight of respondents with their shoes taken off and their eyes fixed straight ahead and their weight measured and recorded to the nearest whole number in kilogram.

\subsection{Calculation of BMI}

The BMI was calculated from the height and weight using the standard formula $\left[\mathrm{BMI}=\right.$ Weight $(\mathrm{kg}) /$ Height $\left.\left(\mathrm{m}^{2}\right)\right]$ and compared with the WHO BMI criteria to classify them into underweight, normal weight, overweight and obese.

\subsection{Data Collection}

Data capture instrument was a self-administered questionnaire that was developed in English and explained in simple terms to the respondents for easy understanding. It was designed based on the specific aims and objectives of the survey. Some of the questions required a simple answer of Yes or No (close ended) while others had answers that were self-explanatory. The respondents were guided as they filled the questionnaires which sought information on socio-demographic characteristics, factors that might affect adolescent food choices, risk factors for obesity, and nutritional status of adolescents. The questionnaire was pretested on adolescents from Bishop Ajayi Crowther Memorial College, Ekpoma to ascertain its construct validity and anthropometric reliability.

\subsection{Ethical Approval}

Ethical clearance was obtained from the Ethics Committee at the Ambrose Alli University College of Medicine, Ekpoma All respondents gave their informed consent before participation in the survey.

\subsection{Data Analysis}

Data were analysed using the Statistical Package for Social Sciences (SPSS) version 17 to generate rates, percentages and proportions. Confidence interval was $95 \%$. The chi square of the Graph Prism software was used to test for statistical significance set as 0.05 .

\section{Results}

From the 430 questionnaires distributed, 406 were retrieved. However, 6 were not satisfactorily completed and so were rejected, leaving 400 for the survey.

Table 1. Sociodemographic characteristics of respondents.

\begin{tabular}{|c|c|c|}
\hline Sociodemographic characteristic & Frequency $(n=400)$ & Percent (\%) \\
\hline \multicolumn{3}{|l|}{ Age (Years) } \\
\hline $10-14$ & 196 & 49.0 \\
\hline $15-19$ & 204 & $51.0 *$ \\
\hline Sex & 239 & $59.8^{*}$ \\
\hline \multicolumn{3}{|l|}{ Male } \\
\hline Female & 161 & 40.2 \\
\hline \multicolumn{3}{|l|}{ Class } \\
\hline JSS2 & 80 & 20.0 \\
\hline JSS3 & 80 & 20.0 \\
\hline SS1 & 80 & 20.0 \\
\hline SS2 & 80 & 20.0 \\
\hline SS3 & 80 & 20.0 \\
\hline \multicolumn{3}{|l|}{ Father's/Guardian's occupation } \\
\hline Civil servant & 115 & 28.8 \\
\hline Trader & 97 & 24.2 \\
\hline Peasant farmer & 48 & 12.0 \\
\hline Student & 12 & 3.0 \\
\hline Unemployed & 8 & 2.0 \\
\hline \multicolumn{3}{|l|}{ Father's/Guardian's level of education } \\
\hline No formal education & 53 & 13.3 \\
\hline Primary & 74 & 18.5 \\
\hline Secondary & 132 & 33.0 \\
\hline Tertiary & 141 & 35.3 \\
\hline \multicolumn{3}{|l|}{ Mother's occupation } \\
\hline Civil servant 121 & & 30.2 \\
\hline Trader & 132 & 33.0 \\
\hline Peasant farmer & 38 & 9.5 \\
\hline Student & 7 & 1.8 \\
\hline Unemployed & 29 & 7.2 \\
\hline Others & 73 & 18.2 \\
\hline \multicolumn{3}{|l|}{ Mother's level of education } \\
\hline No formal education & 64 & 16.0 \\
\hline Primary & 59 & 14.8 \\
\hline
\end{tabular}




\begin{tabular}{lll}
\hline Sociodemographic characteristic & Frequency $(\mathbf{n = 4 0 0})$ & Percent (\%) \\
\hline Secondary & 158 & $39.5^{*}$ \\
Tertiary & 119 & $29.8^{*}$ \\
Average income of your household (Naira) & & \\
$<20000$ monthly & 80 & 20.0 \\
20000-40000 monthly & 86 & 21.5 \\
40000-60000 monthly & 91 & 22.8 \\
$60000-80000$ monthly & 87 & 21.8 \\
$>100000$ monthly & 56 & 14.0 \\
\hline
\end{tabular}

*Higher \% sociodemographic characteristics.

Table 1 shows the sociodemographic characteristics of respondents. Majority of respondents [204(51\%)], fell within the age range of 15-19 years. There were more males [239(59.8\%)] than females [161(40.2\%)]. Respondents were evenly distributed among the schools and in all the classes. It is remarkable that fathers/guardians were mainly civil servants $[115(28.8 \%)]$ with $8(2.0 \%)$ unemployed. They had predominantly tertiary level of education [141(35.2\%)]. However, mother's occupation was mainly trading [132(33\%)] but peasant farmers accounted for [38(9.5\%)] while mothers who were students represented $7(1.8 \%)$. Mothers [158(39.5\%)] had predominantly secondary level of education. Fifty six households (14.0\%) earned a monthly income that was above one hundred thousand Naira.

Table 2. Determinants of dietary choices amongst adolescents.

\begin{tabular}{|c|c|c|}
\hline Determinants & Frequency $(n=400)$ & Percent (\%) \\
\hline \multicolumn{3}{|c|}{ Taking meals to school } \\
\hline No & 208 & $52.0^{*}$ \\
\hline Yes & 192 & 48.0 \\
\hline \multicolumn{3}{|l|}{ Food allergies } \\
\hline No & 236 & $59.0^{*}$ \\
\hline Yes & 151 & 37.8 \\
\hline Not sure & 13 & 3.2 \\
\hline \multicolumn{3}{|c|}{ Consumption of food to which allergy is developed } \\
\hline No & 111 & 73.5 \\
\hline Yes & 40 & 26.5 \\
\hline \multicolumn{3}{|c|}{ Nutritional information and advertisements in the mass media } \\
\hline No & 153 & 38.2 \\
\hline Yes & 247 & $61.8^{*}$ \\
\hline \multicolumn{3}{|l|}{ Food taboo } \\
\hline No & 198 & 49.5 \\
\hline Yes & 202 & $50.5^{*}$ \\
\hline \multicolumn{3}{|c|}{ Food choices based on taste } \\
\hline No & 115 & $28.2^{*}$ \\
\hline Yes & 285 & $71.2^{*}$ \\
\hline \multicolumn{3}{|l|}{ Culture } \\
\hline No & 177 & 44.2 \\
\hline Yes & 223 & $55.8^{*}$ \\
\hline
\end{tabular}

*Higher \% determinants.

Majority [208(52\%)], of respondents did not take meals to school while 192(48\%) did (Table 2). Food allergy was observed amongst 151(37.8\%) respondents, however $236(59 \%)$ were not allergic. Among the respondents who experienced allergy to foods, most of them [111(73.5\%)] no longer consumed such foods whereas $40(26.5 \%)$ still did. Majority [247(61.8\%)], attested to the fact that nutritional information and advertisements in the mass media (television, radio, newspapers, internet) affected their food choices, whereas 153(38.2\%) held opposite view. Food taboos influenced choice of food in about half of the respondents [202(50.5\%)], as opposed to $198(49.5 \%)$ who did not have any such inhibitions. Culture was also observed to be a major determinant of food choices amongst respondents as $223(55.8 \%)$ were of the opinion that culture affected their food choices but 117(44.2\%) were of contrary opinion.
Table 3. Determinants of dietary choices amongst adolescents who take meals to school.

\begin{tabular}{lll}
\hline Diet determinants & Frequency $(\mathbf{n = 1 9 2})$ & Percent $(\%)$ \\
\hline Father & 23 & 12.0 \\
Mother & 144 & $75.0^{*}$ \\
Brother & 6 & 3.1 \\
Sister & 8 & 4.2 \\
Uncle & 2 & 1.0 \\
Aunty & 0 & 0 \\
Others & 9 & 4.7 \\
\hline
\end{tabular}

*Mothers were mostly responsible for food choices.

From Table 3, it is observed that amongst respondents who took meals to school, mothers [144(75\%)] were the major determinants of the type of food taken while fathers (23), sisters (8) and brother (6) constituted $12.0 \%, 4.2 \%$ and $3.1 \%$, respectively. 
Table 4. Adolescents' dietary habits.

\begin{tabular}{lll}
\hline Variable & Frequency $(\mathbf{n = 4 0 0})$ & Percent (\%) \\
\hline Number of meals per day & & \\
Once & 2 & 0.5 \\
Twice & 121 & 30.2 \\
Thrice & 277 & $69.2^{*}$ \\
Others & 0 & 0 \\
Skip breakfast & & \\
No & 243 & $60.7^{*}$ \\
Yes & 157 & 39.2 \\
Eating in-between meals & & \\
No & 163 & 40.7 \\
Yes & 237 & $59.2^{*}$ \\
Reasons for skipping breakfast & & \\
I don't want to be late for school & 66 & 42.0 \\
I don't want to be fat & 26 & 16.7 \\
I don't want to be tired & 0 & 0 \\
Fasting and praying & 1 & 0.6 \\
No appetite & 17 & 10.8 \\
No reason & 21 & 13.4 \\
Frequency of eating junk & & \\
Never & 66 & 16.5 \\
1-2 times & 146 & 36.5 \\
3-5 times & 119 & 29.8 \\
6-10 times & 33 & 8.2 \\
>10 times & 29 & 7.2 \\
i don't know & 7 & 1.8 \\
\hline
\end{tabular}

*Higher $\%$ determinants.

Table 4 displays the dietary habits of respondents. Majority of respondents ate more than once in a day as $121(30.2 \%)$ ate twice in a day and $277(69.2 \%)$ ate thrice daily. A good number [243(60.7\%)], claimed not to skip breakfast whereas $157(39.2 \%)$ did. Possible reasons for skipping breakfast by subjects included not wanting to be late for school [66(42.0\%)], dislike for obesity [26(16.7\%)], no appetite $[17(10.8 \%)]$ and prayer and fasting [1(0.6\%)]. However, 21(13.4\%) gave no reason. Many [237(59.2\%)] responded positively to eating in-between meals. Most respondents ate junk foods like fried fast foods, carbonated beverages, sweets, chocolates, doughnuts, ice cream etc. many times a month: 146(36.5\%) ate junks 1-2times, $119(29.8 \%)$ ate junks 3-5times and $29(7.2 \%)$ ate junk more than 10 times.

Table 5. Body mass index of subjects.

\begin{tabular}{lll}
\hline & Frequency $(\mathbf{n}=\mathbf{4 0 0})$ & Percent $(\mathbf{\%})$ \\
\hline Body mass index $\left(\mathrm{kg} / \mathrm{m}^{2}\right)$ & & \\
$<18$ & 96 & 24.0 \\
$18.0-24.9$ & 288 & $72.0^{*}$ \\
$25-29.9$ & 12 & 3.0 \\
$>30$ & 4 & 1.0 \\
\hline
\end{tabular}

*Normal BMI.

The BMI of most respondents [288(72\%)] was observed to lie between the range of $18.0-29.9 \mathrm{~kg} / \mathrm{m}^{2}$ while $96(24 \%)$, $12(3 \%)$ and $4(1 \%)$ had BMIs of $<18,25-29.9$ and $>30$, respectively (Table 5).

Table 6. Relationship between sociodemographic characteristics of respondents and body mass index.

\begin{tabular}{|c|c|c|c|c|c|c|c|c|}
\hline \multirow{2}{*}{ Body mass index $\left(\mathrm{kg} / \mathrm{m}^{2}\right)$} & \multicolumn{2}{|c|}{$<18$ (underweight) } & \multicolumn{2}{|c|}{ 18.0-24.9 (Normal weight) } & \multicolumn{2}{|c|}{ 25-29.9 (Overweight) } & \multicolumn{2}{|c|}{$>30$ (Obesity) Significance } \\
\hline & $\mathbf{N}$ & $(\%)$ & $\mathbf{N}$ & $(\%)$ & $\mathbf{n}$ & $(\%)$ & $\mathbf{n}$ & (\%) Test \\
\hline \multicolumn{9}{|l|}{ Age in years } \\
\hline Early adolescents (10-14) & 53 & $(27.0)$ & 137 & $(69.9)$ & 5 & $(2.6)$ & 1 & $(0.5) \chi 2=3.708$ \\
\hline Late adolescents (15-19) & 43 & $(21.1)$ & 151 & $(74.0)$ & 7 & $(3.4)$ & 3 & $(1.5) \mathrm{df}=3, \mathrm{p}=0.447>0.05$ \\
\hline Male & 54 & $(122.6)$ & 174 & $(72.0)$ & 8 & (3.3) & 3 & $(1.3) \mathrm{df}=3 \mathrm{p}=0.432>0.05$ \\
\hline Female & 42 & $(26.1)$ & 114 & $(70.8)$ & 4 & $(2.5)$ & 1 & $(0.6) \mathrm{df}=3, \mathrm{p}=0.647>0.05$ \\
\hline \multicolumn{9}{|l|}{ Class } \\
\hline JSS3 & 12 & $(15.0)$ & 65 & $(81.2)$ & 3 & $(3.8)$ & 0 & $(0) \mathrm{df}=12 \mathrm{p}=0.000<0.05$ \\
\hline SS1 & 11 & $(13.8)$ & 66 & $(82.5)$ & 2 & $(2.5)$ & 1 & $(1.2)$ \\
\hline $\mathrm{SS} 2$ & 15 & $(18.8)$ & 63 & $(78.8)$ & 0 & $(0)$ & 2 & $(2.5)$ \\
\hline SS3 & 21 & $(26.2)$ & 54 & $(67.5)$ & 5 & $(6.2)$ & 0 & $(0)$ \\
\hline \multicolumn{9}{|l|}{$\begin{array}{l}\text { Father's/Guardian's level of } \\
\text { education }\end{array}$} \\
\hline No formal education & 20 & $(38.5)$ & 33 & $(63.5)$ & 0 & $(0)$ & 0 & (0) $\chi 2=18.305$ \\
\hline Secondary & 28 & $(21.2)$ & 98 & $(74.2)$ & 4 & $(3.0)$ & 2 & $(1.5)$ \\
\hline Tertiary & 28 & $(19.8)$ & 104 & $(73.8)$ & 7 & $(5.0)$ & 2 & $(1.4)$ \\
\hline \multicolumn{9}{|c|}{ Father's/Guardian's occupation } \\
\hline Civil servant & 15 & $(13.0)$ & 91 & $(79.1)$ & 7 & $(6.1)$ & 2 & $(1.7) \chi 2=30.631$ \\
\hline Trader & 25 & $(25.8)$ & 67 & $(69.1)$ & 4 & $(4.1)$ & 1 & $(1.0) \mathrm{df}=15, \mathrm{p}=0.165>0.05$ \\
\hline Peasant farmer & 17 & $(35.4)$ & 30 & $(62.5)$ & 0 & $(0)$ & 1 & $(2.1)$ \\
\hline Student & 4 & $(33.3)$ & 8 & $(66.7)$ & 0 & $(0)$ & 0 & $(0)$ \\
\hline Unemployed & 3 & $(37.5)$ & 5 & $(62.5)$ & 0 & $(0)$ & 0 & $(0)$ \\
\hline Others & 32 & $(26.7)$ & 87 & $(72.5)$ & 1 & $(0.8)$ & 0 & $(0)$ \\
\hline \multicolumn{9}{|l|}{ Mother's level of education } \\
\hline No formal education & 21 & $(32.8)$ & 43 & $(67.2)$ & 0 & $(0)$ & 0 & (0) $\chi 2=21.093$ \\
\hline Primary & 19 & $(32.2)$ & 38 & $(64.4)$ & 1 & $(1.7)$ & 1 & $(1.7) \mathrm{df}=9, \mathrm{p}=0.175>0.05$ \\
\hline Secondary & 39 & $(24.7)$ & 114 & $(72.2)$ & 4 & $(2.5)$ & 1 & $(0.6)$ \\
\hline Tertiary & 17 & $(14.2)$ & 93 & $(78.2)$ & 7 & $(5.9)$ & 2 & $(1.7)$ \\
\hline Mother's occupation & & & & & & & & \\
\hline
\end{tabular}




\begin{tabular}{|c|c|c|c|c|c|c|c|c|}
\hline \multirow{2}{*}{ Body mass index $\left(\mathrm{kg} / \mathrm{m}^{2}\right)$} & \multicolumn{2}{|c|}{$<18$ (underweight) } & \multicolumn{2}{|c|}{ 18.0-24.9 (Normal weight) } & \multicolumn{2}{|c|}{ 25-29.9 (Overweight) } & \multicolumn{2}{|c|}{$>30$ (Obesity) Significance } \\
\hline & $\mathbf{N}$ & $(\%)$ & $\mathbf{N}$ & $(\%)$ & $\mathbf{n}$ & $(\%)$ & $\mathbf{n}$ & (\%) Test \\
\hline Civil servant & 17 & $(14.0)$ & 96 & $(79.3)$ & 7 & $(5.8)$ & 1 & $(0.8) \chi 2=26.543$ \\
\hline Trader & 41 & $(31.1)$ & 85 & $(64.4)$ & 4 & $(3.0)$ & 2 & $(1.5) \mathrm{df}=15 \mathrm{p}=0.149>0.05$ \\
\hline Peasant farmer & 14 & $(36.8)$ & 22 & $(57.9)$ & 1 & $(2.6)$ & 1 & $(2.6)$ \\
\hline Student & 1 & $(14.3)$ & 6 & $(85.7)$ & 0 & (0) & 0 & $(0)$ \\
\hline Unemployed & 4 & (13.8) & 25 & $(86.2)$ & 0 & (0) & 0 & (0) \\
\hline Others & 19 & $(26.0)$ & 54 & $(74.0)$ & 0 & (0) & 0 & (0) \\
\hline$<20000$ monthly & 30 & $(37.5)$ & 48 & $(60.0)$ & 1 & $(1.2)$ & 1 & $(1.2)^{*} \chi 2=43.148$ \\
\hline $20000-40000$ monthly & 24 & (27.9) & 60 & $(69.8)$ & 1 & $(1.2)$ & 1 & (1.2) $\mathrm{df}=12, \mathrm{p}=0.002<0.05$ \\
\hline 40000-60000 monthly & 16 & $(17.6)$ & 70 & $(76.9)$ & 4 & $(4.4)$ & 1 & $(1.1)$ \\
\hline $60000-80000$ monthly & 22 & $(25.2)$ & 64 & $(73.6)$ & 0 & $(0)$ & 1 & $(1.1)$ \\
\hline$>100000$ monthly & 4 & $(7.1)$ & 46 & $(82.1)$ & 6 & $(10.7)$ & 0 & $(0)$ \\
\hline
\end{tabular}

*Significant relationship between BMI and classes as well as household average income.

From Table 6, a higher proportion [53(27.0\%)] of early adolescents was underweight compared to the underweight late adolescents $[43(2.1 \%)]$. However, more late adolescents $151(74.0 \%)$ were of normal weight and overweight $7(3.4 \%)$ as compared to the early adolescents with $137(69.9 \%)$ normal weight and 5(2.6\%) overweight, respectively. There was no statistical significant association between the age and BMI of respondents.

Fifty four $(122.6 \%)$ male respondents were underweight, while $174(72 \%)$ had normal weight, $8(3.3 \%)$ were overweight and $3(1.3 \%)$ were obese compared to the females who had $42(26.1 \%), 114(70.8 \%), 4(2.5 \%)$ and $1(0.6 \%)$ underweight, normal weight, overweight and obesity, respectively. There was no significant association between sex and BMI.

Amongst the respondents in JSS2, 37(46.2\%) were underweight, $40(50.0 \%)$ had normal weight, $2(2.5 \%)$ were overweight and $1(1.2 \%)$ was obese compared to the other classes. There was a statistical significant difference between the classes and BMI.

Amongst respondents who had fathers/guardians with tertiary level of education, 28(19.8\%) were underweight, $104(73.8 \%)$ had normal weight, $7(5.0 \%)$ were overweight and $2(1.4 \%)$ were obese compared with the others with no formal education, primary education and secondary education. There was no statistical significant association between the father's/guardian's level of education and BMI.

Amongst respondents whose fathers/guardians were traders, 25(25.8\%) were underweight, 67(69.1\%) had normal weight, $4(4.1 \%)$ were overweight and $1(1.0 \%)$ was obese compared to the others. Of note, respondents whose fathers/guardians were civil servants were found to have the highest number of adolescents with normal weight 91(79.1\%) although there was no statistical significant association between the father's/guardian's occupation and BMI.

A higher proportion of respondents whose mothers/guardians had secondary level of education were found to be of normal weight 114(72.2\%), whereas those with no formal education had the lowest number of adolescents [43(10.8\%)] that fell within normal weight. Also, mothers/guardians with tertiary level of education were found to have respondents with the highest number of overweight 7(5.95) and obese 2(1.7\%) compared to those with no formal education who had neither overweight nor obese respondents. There was no statistical significant difference between the mother's/guardian's level of education and BMI.

Amongst respondents whose mothers were peasant farmers, $14(36.8 \%)$ were underweight, $22(57.9 \%)$ had normal weight, $1(2.6 \%)$ was overweight and $1(2.6 \%)$ was obese compared to other mothers' occupations. There was no statistical significant association between the mother's occupation and BMI.

Respondents whose average household income fell between 20,000 and 40,000 Naira had 24(27.9\%) underweight, $60(69.7 \%)$ normal weight, $1(1.2 \%)$ was overweight and 1(1.6\%) was obese. Respondents whose average household income was more than 100,000 Naira per month had the highest number of overweight adolescents $6(10.7 \%)$ compared to those whose families earned less than 20,000 thousand Naira monthly. There was a statistical significant difference between the average income of each household and BMI.

\section{Discussion}

The more males in this survey may not be unconnected with the gender bias in some Nigerian communities and cultures that place more emphasis on male child education and health [24-26].

Accordingly, respondents' mothers who had no formal education and those who receive primary level education were $16.0 \%$ and $14.8 \%$, respectively. This is a sorry state of affairs because substandard education is correlated with poor health outcomes for women and by extension, their children [24]. Girl child education must be a priority because of its impact on all aspects of human development. To justify the foregoing, out of 192 respondents who took food to school, respondents' mothers were the major determinants of the type of food taken to school. Interestingly too, a higher proportion of respondents whose mothers/guardians had secondary education were found to be normal weight whereas those with no formal education had the lowest number of normal weight respondents, although the association with BMI was not statistically significant.

The relatively high percentage $(24.0 \%)$ of underweight 
respondents (as shown by the BMI), has demonstrated that malnutrition, especially undernutrition, is a serious challenge in this semi-urban university community. This percentage may be higher in other surrounding rural/semi-urban districts burdened by high unemployment, insecurity, poverty and other deprivations. For example, in their study in Makurdi, Nigeria, Une and Soumay [27] found the prevalence rate of undernutrition to be $50.66 \%$ in school children and schools located in the slums part recorded the highest rate. In the same vein, Ojofeitimi et al [28], who studied adolescents in Olorunda Local Government Area of Osun State, Nigeria, found $42 \%$ were underweight using the BMI.

From this survey, possible causes of this undernutrition may be multiple. The average monthly household income of respondents, which was relatively low compared to developed societies, was significantly associated with BMI. Cultural practices and food taboos influenced the dietary habits of $55.8 \%$ and $50.5 \%$ of respondents, respectively. Tellingly, unhealthy cultural beliefs and practices cum food taboos have been reported to have negative impact on the health of Nigerian communities. Most tabooed food items, including those rich in proteins, calories, vitamins and minerals, work against the most vulnerable members of the society, particularly pregnant women and children [29-31]. Similarly, food allergy, meal skipping, junk food eating, dieting particularly by females because of weight concerns, poor quality and unsatisfactory taste of family meals as well as alluring mass media advertisement, have contributed their bit to this disturbing undernutrition phenomenon [3-4, 8-11, $13-16,32]$.

\section{Conclusion}

Abundant evidence indicates a complex interplay between nutrition and health. The period of adolescence is the most challenging in human development as it involves both important physical and psychological changes that may influence not only their future health but also the risk of developing major chronic diseases in adulthood if adequate nutrition is not received.

In contrast to the rising prevalence of obesity worldwide, this survey has demonstrated that malnutrition, especially undernutrition, is a challenge in this environment. The monthly income of Nigerian workers should be increased to enable each household feed adequately. Intensified nutrition education, provision of adequate/healthy diets as well as motivational strategies are imperatives to control and prevent malnutrition and its related health consequences in this adolescent population-tomorrows adults.

\section{References}

[1] WHO, 2005. Nutrition in Adolescents-Issues and Challenges for the Health Sector. WHO, Geneva, WHO Press, ISBN 9241593660. Available at http://www.who.int Accessed on May 2, 2018.
[2] Omobuwa O, Alebiosu CO, Olajide FO, Adebimpe WO, 2014 Assessment of nutritional status of in-school adolescents in Ibadan, Nigeria. South Afr Fam Pract 56(4): 246-250. org./10.1080/20786190.2014.9533891.

[3] Nwokoro SO, Ifada K, Onochei O, Olomu JM, 2006. Anthropometric assessment of nutritional status and growth of 10-20 years old individuals in Benin City (Nigeria) metropolis Pak J Nutr 5:117-121.

[4] Prajapati M, Bala DV, Tiwari H, 2011. A study of nutritional status and high risk behaviour of adolescents in Ahmedabad: a cross sectional study. Healthline 2(1):2229-339X.

[5] Onimawo IA, 1998. Activity pattern and energy expenditure of male students in a Nigerian College of Agriculture. Nutr Res 18:963-973.

[6] Stang J S, Stotmeister B, 2017. Nutrition in adolescence in: Temple N, Wilson T, Bray G (eds) Nutrition guide for physicians and related healthcare professionals. Nutrition and health. Humana Press Cham, ISBN 978-3-319-49928-4. https://doi.og/10.10071978-3-319-499929-1_4

[7] Ogechi UP, Akhakhia OI, Ugwunna, UA, 2007. Nutritional status and energy intake of adolescents in Umuahia Urban, Nigeria. Pak J Nutr 6:641-646.

[8] Ejike ECCC, Ugwu EC, Ezeanyika USL, 2010. Physical growth and nutritional status of a cohort of semi-urban Nigerian adolescents. Pak J Nutr 9:392-397.

[9] Livingstone MBE, 2004. Issues in dietary assessment in children and adolescents. Br J Nutr 92:5213-5222.

[10] Gebremariam H, Seid O, Assefa H, 2015. Assessment of nutritional status and associated risk factors among school going adolescents of Mekelle City, Northern Ethiopa. Int J Nutr Food Sc 4(1): 118-124. Doi: 10.116481j.ijnfs.20150401.28.

[11] Roba K T, Abdo M, Wakayo T, 2016. Nutritional status and its associated factors among school adolescents girls in Adama City, Central Ethiopa. J Nutr Food Sci 6:3. http://doi.org/10.4172/2155-96001000493.

[12] Videon TM, Manning CK, 2003. Influences on adolescent eating patterns: The importance of family meals. J Adolesc Health 32:365-373.

[13] Grygiel-Gòriak B, Tomczak A, Krulikowsha N, Przyslawski J, Seraszek A, Kaczmarek E, 2016. Physical activity, nutritional status, and dietary habits of students of a medical university. Sport Sci Health 12:261-267. Doi 10.1007/511332-016-0285$\mathrm{x}$.

[14] Dapin LN, Noudoui C, Janlert U, Haglin L, 2005. Adolescents' food habits and nutritional status in urban and rural areas in Cameroon, Africa. Scand J Nutr 49(4):151-158.

[15] Yunusa I, Ezeanyika LUS, 2013. Dietary intake, anthropometry and nutritional status of adolescents in Nigeria: A review. Asian J Sci Res 6(1):16-26. DOI:10.3923/ ajsr. 2013.16.26

[16] Poudel P, 2018. Junk food consumption and its association with BMI among school adolescents. Int $\mathrm{J}$ Nutr Food Sc 7(3):90-93. Doi:10.116448/j.ijnfs.20180703.12.

[17] Stang J, 2010. Assessment of nutritional status and motivation to make behaviour changes among adolescents. The American Dietetic Association, Sp.13. 
[18] Deka M K, Malhotra A K, Yadav R, Gupta S, 2015. Dietary pattern and nutritional deficiencies among urban adolescents. J Fam Med prim care 4(3): 364-368. Doi: 10. 4103122494863.161319 .

[19] Das J K, Salam A R, Thornburg K L, Prentice A M, Campsi S, Lassi Z S, Koletzko B, Bhutta Z A, 2017. Nutrition in adolescents: physiology, metabolism, and nutritional needs. Ann N Y Acad Sci 139(1):21-33. https://doi.org/10.1111/nya.1330.

[20] De Onis M, Habicht JP, 1997. Anthropometric reference data for international use: recommendations from a WHO expert committee. Food Nutr Bull 18:179-189.

[21] Blum RW, 1991. Global trends in adolescents health. J Am Med Assoc (JAMA) 265:2711-2719.

[22] Maddaleno M, Silber TJ, 1993. An epidemiological view of adolescents' health in Latin America. J Adolesc Health 14:595-604.

[23] Kish L, 1965. Survey Sampling. New York: John Wiley and Sons, Inc.

[24] Nmadu G, Avidime S, Oguntunde O, Dashe V, Abdukarim B, Madara M, 2010. Girl child education: Rising to the challenge. Afr J Reprod Health (Special Issue) 14(3):107-112.

[25] Dauda RO, 2007. Female education and Nigeria's development strategies: Lots of talk, little action. Ind J Gender Studies 14(3):461-478.
[26] Iyalomhe G B S, Iyalomhe S I, 2012. Health-seeking behaviour of rural dwellers in Southern Nigeria: Implications for healthcare professionals. Int J Trop Dis Health 2(2):62-71.

[27] Une EA, Soumay RH 2009. Assessment of nutritional status of school children in Makurdi, Benue State. Pak J Nutr 8(5): 691-694.

[28] Ojofeitimi EO, Olugbenga-Bello A, Adekanle DA, Adeomi AA, 2011. Pattern and determinants of obesity among adolescent females in private and public schools in Olorunda Local Government Area of Osun State, Nigeria: a comparative study. J Public Health Afr 2(1):e11. Doi:104081/jphia.2011.e11.

[29] Onuorah CE, Ayo JA, 2003. Food taboos and their nutritional implications on developing nations like Nigeria: A review. Nutr Food Sc 33(5):235-240. http://doi.org/10.1108/00346650310499467.

[30] Ogbeide O, 1974. Nutritional hazards of food taboos and preferences in Mid-West Nigeria. Am J Clin Nutr 27:213-216.

[31] Ekwochi U, Osuorah CDI, Ndu IK, Ifediora C, Asinobi IN, Eke CB, 2016. Food taboos and myths in South Eastern Nigeria: The belief and practice of mothers in the region. J Ethnobiol Ethnomed 12:7. https://doi.org/10.1186/513002016-0079-x.

[32] Chugh R, Puri S 2001. Affluent girls of Delhi: Eating and weight concerns. Br J Nutr 86:535-542. 